\title{
Fabrication and Enhanced Thermoelectric Properties of Alumina Nanoparticle-Dispersed $\mathrm{Bi}_{0.5} \mathrm{Sb}_{1.5} \mathrm{Te}_{3}$ Matrix Composites
}

\author{
Kyung Tae Kim and Gook Hyun Ha \\ Powder \& Ceramic Materials Division, Korea Institute of Materials Science, 797 Changwon-daero, Seongsan-gu, \\ Changwon-si, Gyeongnam 642-831, Republic of Korea
}

Correspondence should be addressed to Kyung Tae Kim; ktkim@kims.re.kr

Received 25 June 2013; Revised 14 September 2013; Accepted 14 October 2013

Academic Editor: Hyung-Ho Park

Copyright (C) 2013 K. T. Kim and G. H. Ha. This is an open access article distributed under the Creative Commons Attribution License, which permits unrestricted use, distribution, and reproduction in any medium, provided the original work is properly cited.

\begin{abstract}
Alumina nanoparticle-dispersed bismuth-antimony-tellurium matrix $\left(\mathrm{Al}_{2} \mathrm{O}_{3} / \mathrm{BST}\right)$ composite powders were fabricated by using ball milling process of alumina nanoparticle about $10 \mathrm{~nm}$ and p-type bismuth telluride nanopowders prepared from the mechanochemical process (MCP). The fabricated $\mathrm{Al}_{2} \mathrm{O}_{3} / \mathrm{BST}$ composite powders were a few hundreds of nanometer in size, with a clear $\mathrm{Bi}_{0.5} \mathrm{Sb}_{1.5} \mathrm{Te}_{3}$ phase. The composite powders were consolidated into p-type bulk composite by spark plasma sintering process. High-resolution TEM images reveal that alumina nanoparticles were dispersed among the grain boundary or in the matrix grain. The sintered $0.3 \mathrm{vol} . \% \mathrm{Al}_{2} \mathrm{O}_{3} / \mathrm{BST}$ composite exhibited significantly improved power factor and reduced thermal conductivity in the temperature ranging from 293 to $473 \mathrm{~K}$ compared to those of pure BST. From these results, the highly increased ZT value of 1.5 was obtained from $0.3 \mathrm{vol} . \% \mathrm{Al}_{2} \mathrm{O}_{3} / \mathrm{BST}$ composite at $323 \mathrm{~K}$.
\end{abstract}

\section{Introduction}

Bismuth telluride $\left(\mathrm{Bi}_{2} \mathrm{Te}_{3}\right)$-based alloys are very attractive thermoelectric (TE) materials due to their high energy conversion efficiency at ambient temperature for achieving power generation without requiring any driving parts or cooling systems in electronic devices [1]. It is well known that the TE conversion efficiency of thermoelectric devices is expressed as the dimensionless figure-of-merit, ZT, which is calculated from $T\left(\alpha^{2} / \rho \kappa\right)$, where $T$ is the absolute temperature, $\alpha$ is the Seebeck coefficient, and $\rho$ and $\kappa$ are respectively the electrical resistivity and thermal conductivity. Thus, current researches have concentrated on obtaining a reduced thermal conductivity and increased electrical properties, respectively in order to enhance ZT values. Nanostructuring of the microstructure and the incorporation of nanoparticles in bismuth telluride TE alloys have been reported as efficient approaches to achieve high ZT value by controlling carrier and phonon transporting behaviors [2-5].

Recently, many researchers report that controlling electrical conductivity and/or the Seebeck coefficient can be simultaneously improved by an electron filtering through the use of a composite structure consisting of TE materials and nanoinclusions such as $\mathrm{SiC}$ nanoparticles, and carbon nanotubes [6-10]. Furthermore, the concept of the reduction in the lattice thermal conductivity more than increasing electrical resistivity has been widely accepted to improve the ZT value, because phonons are effectively blocked while carriers pass through the dispersed nanoparticles below $10 \mathrm{~nm}$ in size due to the difference in the wavelengths between the phonons ad carriers. However, most of the bismuth telluride matrix composite is based on binary $\mathrm{Bi}_{2} \mathrm{Te}_{3}$-based materials $[6,8,9]$. There have been a few studies on achieving high $\mathrm{ZT}$ values of ternary $\mathrm{Bi}_{2} \mathrm{Te}_{3}$ matrix composite including the separately added nanoparticles.

In this study, we report thermoelectric properties of alumina nanoparticle-dispersed p-type $\mathrm{Bi}_{0.5} \mathrm{Sb}_{1.5} \mathrm{Te}_{3}$ matrix composite fabricated by high-energy ball milling process and followed by spark plasma sintering (SPS) process. The composites sintered from 0.3 vol. $\% \mathrm{Al}_{2} \mathrm{O}_{3} / \mathrm{BST}$ composite powders show significantly increased ZT value, 1.5 compared to 1.1 of pure BST materials. 

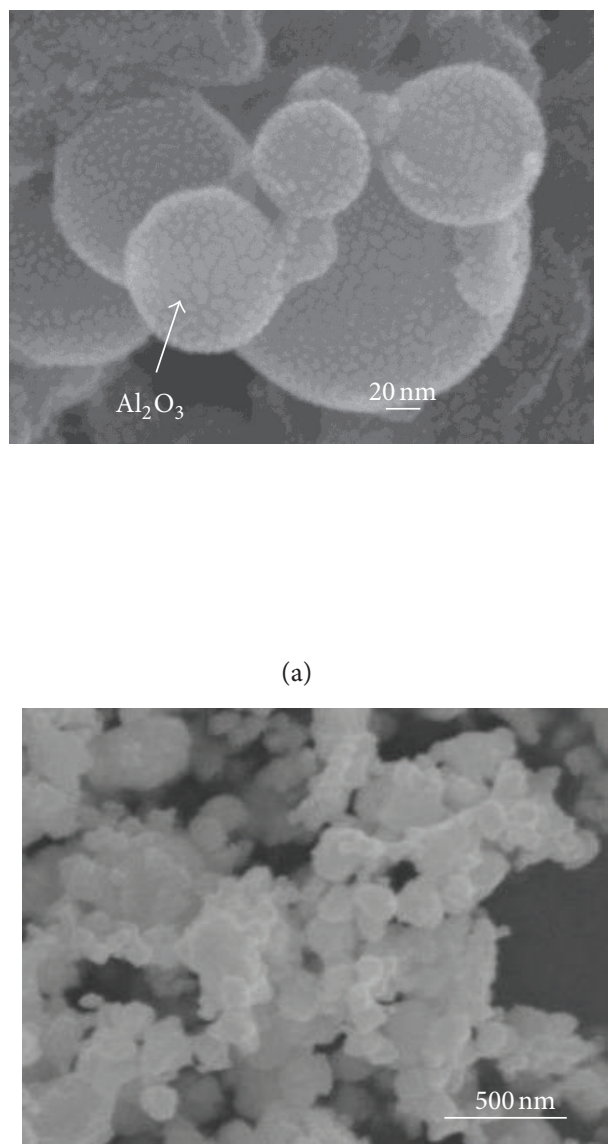

(c)

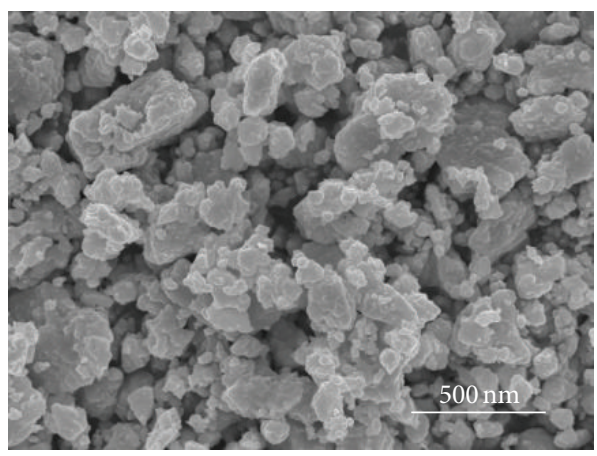

(e)

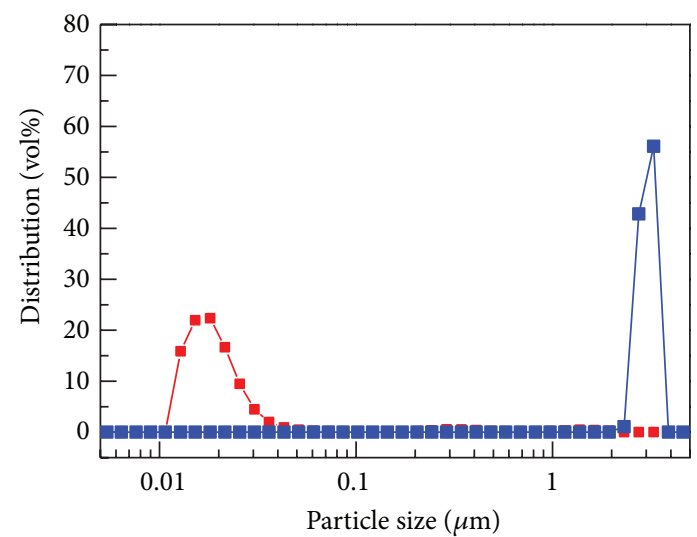

$--\mathrm{Al}_{2} \mathrm{O}_{3} 50 \mathrm{wt} \%$ in solvent

$\rightarrow \mathrm{Al}_{2} \mathrm{O}_{3} 3.0 \mathrm{wt} \%$ in solvent

(b)

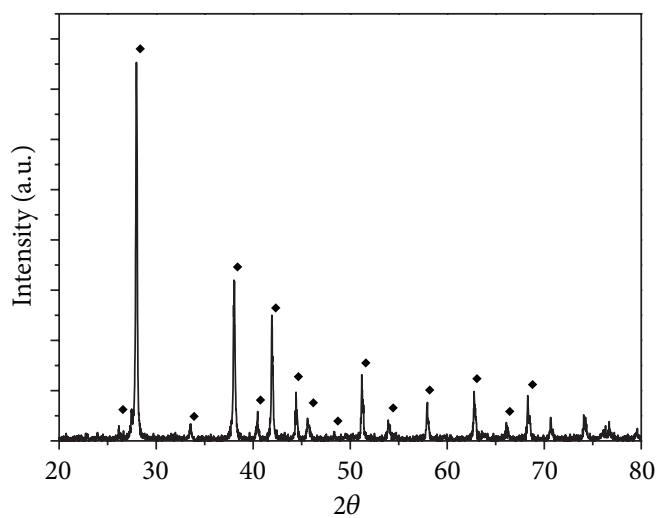

- $\mathrm{Bi}_{0.5} \mathrm{Sb}_{1.5} \mathrm{Te}_{3}: 49-1713$

(d)

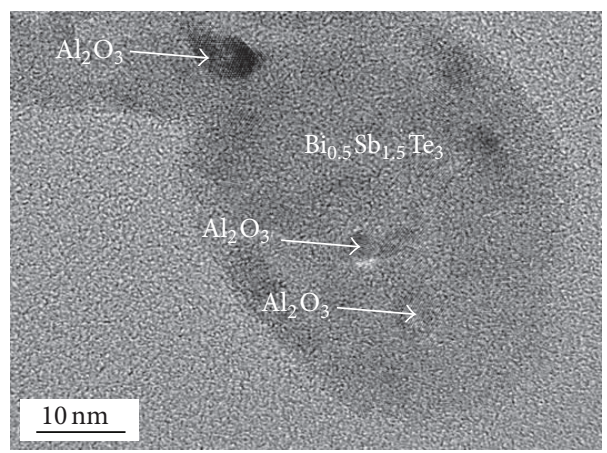

(f)

FIGURE 1: (a) FE-SEM image of $\mathrm{Al}_{2} \mathrm{O}_{3}$ nanoparticles used in this study, (b) size distribution of the nanoparticles in solvent with different concentration, (c) surface morphology of p-type $\mathrm{Bi}_{0.5} \mathrm{Sb}_{1.5} \mathrm{Te}_{3}$ nanopowders prepared from MCP, (d) XRD patterns of fabricated p-type $\mathrm{Bi}_{0.5} \mathrm{Sb}_{1.5} \mathrm{Te}_{3}$ nanopowders, (e) the surface morphology of the fabricated $\mathrm{Al}_{2} \mathrm{O}_{3} / \mathrm{BST}$ composite powders, and (f) TEM image showing $\mathrm{Al}_{2} \mathrm{O}_{3}$ nanoparticles dispersed in BST matrix powders.

\section{Experimental Procedure}

$\mathrm{Al}_{2} \mathrm{O}_{3}$ nanoparticles used in this study have size of about $10 \mathrm{~nm}$ and $\alpha$-phase. They were chemically treated into a stable colloidal solution in a solvent by adding a surfactant. We used mechanochemical process to synthesize p-type Bi-SbTe (BST) powders with $\mathrm{Bi}_{0.5} \mathrm{Sb}_{1.5} \mathrm{Te}_{3}$ phase from a solution of $\mathrm{Bi}_{2}\left(\mathrm{SO}_{4}\right)_{3}, \mathrm{SbCl}_{3}$, and $\mathrm{TeO}_{2}$ powders that are supplied from byproducts of $\mathrm{Cu}$ refining process. During the MCP, $\mathrm{Bi}$ sulfate, $\mathrm{Sb}$ chloride, and Te oxide were homogeneously 


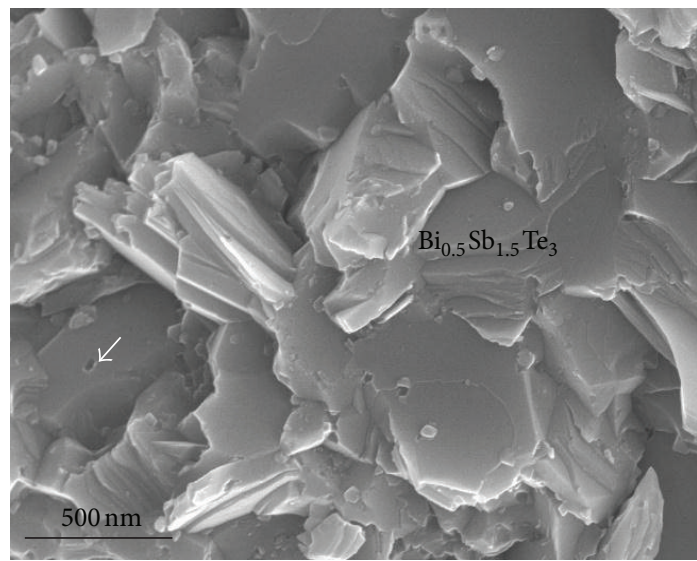

(a)

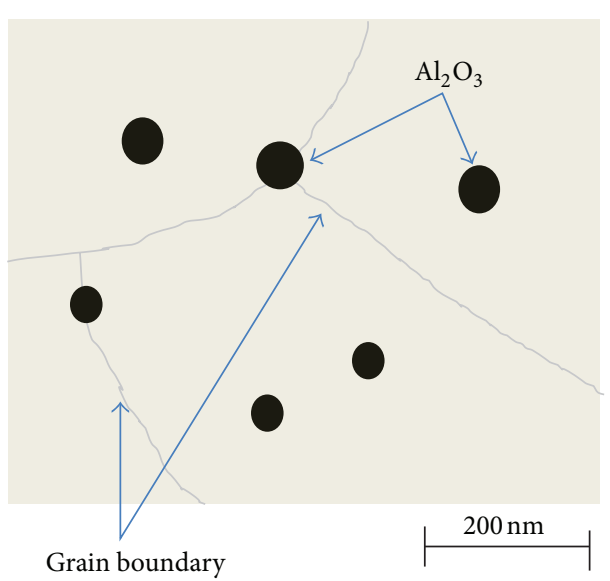

(c)

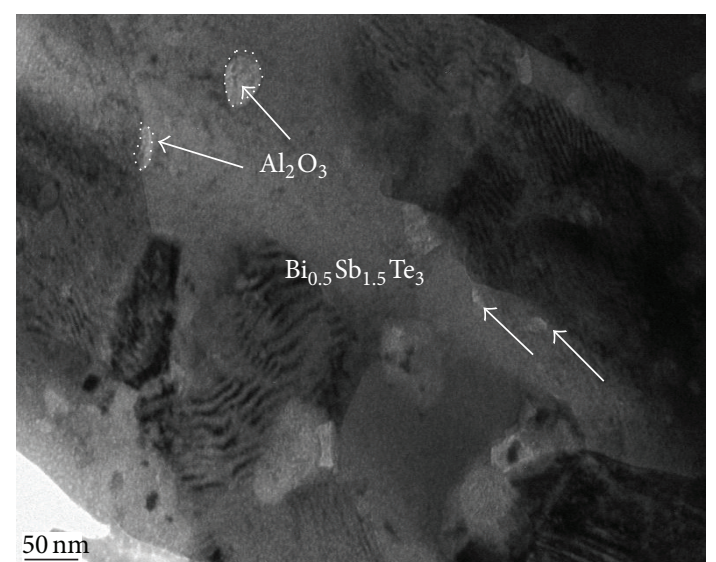

(b)

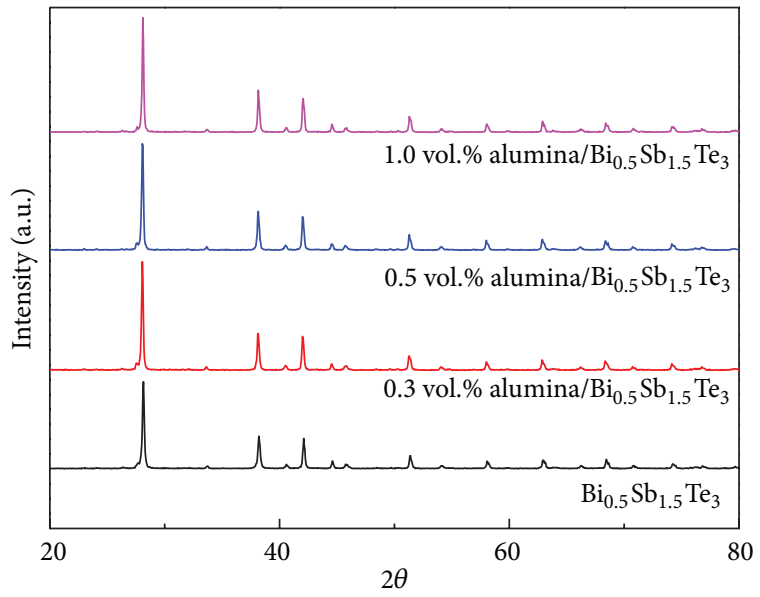

(d)

Figure 2: (a) FE-SEM image of fracture surface of the sintered $\mathrm{Al}_{2} \mathrm{O}_{3} / \mathrm{BST}$ composite, (b) TEM image of $\mathrm{Al}_{2} \mathrm{O}_{3} / \mathrm{BST}$ composite, (c) schematic illustration of the microstructure of the composite, and (d) XRD patterns of the composites compared with pure BST material.

mixed by ball milling process, and the milled powders were subsequently dried and calcinated into complex oxide materials. Finally, the calcinated powders were reduced to Bi-Sb-Te-based TE powders (for more detailed experimental procedures, refer to [11]). The synthesized $\mathrm{Bi}_{0.5} \mathrm{Sb}_{1.5} \mathrm{Te}_{3}$ powders were mixed with $\mathrm{Al}_{2} \mathrm{O}_{3}$ nanoparticles by a high-energy ball milling process (Planetary Milling Machine, Fritsch) in a hexane solvent. The $\mathrm{Al}_{2} \mathrm{O}_{3} / \mathrm{BST}$ composite powders were consolidated by a spark plasma sintering process (SPS, Weltech Co., WL-15-400, Republic of Korea) at $350^{\circ} \mathrm{C}$ for $10 \mathrm{~min}$ [12]. The phase of the powders and consolidated bulk was characterized by the X-ray diffraction method (model no. X'pert MPD 3040 with $\mathrm{CuK} \alpha$ radiation). The microstructures of the powders and bulk composites were analyzed by field emission scanning electron microscopy (FESEM). Embedding of $\mathrm{Al}_{2} \mathrm{O}_{3}$ nanoparticles in BST matrix powders was characterized by a high-resolution transmission electron microscopy (HR-TEM, FE-TEM, $200 \mathrm{kV}$ JEM2100F, JEOL). The weigh percent of the $\mathrm{Al}_{2} \mathrm{O}_{3}$ was found to be $0.014 \mathrm{wt} \%$, corresponding to a $0.3 \mathrm{vol} . \% \mathrm{Al}_{2} \mathrm{O}_{3} / \mathrm{Bi}_{0.5} \mathrm{Sb}_{1.5} \mathrm{Te}_{3}$ composite when a density of $3.96 \mathrm{~g} / \mathrm{cc}$ of the $\mathrm{Al}_{2} \mathrm{O}_{3}$ and a density of $6.88 \mathrm{~g} / \mathrm{cc}$ of $\mathrm{Bi}_{0.5} \mathrm{Sb}_{1.5} \mathrm{Te}_{3}$ were applied. The thermoelectric properties of the sintered body were characterized using ZEM-3 (Ulvac-Rico), and the relative density was evaluated by Archimedes method. Thermal conductivity of the BST and $\mathrm{Al}_{2} \mathrm{O}_{3} / \mathrm{BST}$ composites was calculated by the thermal diffusivity measured by the laser flash method (LFA457, Netzsch) and the specific heat measured by a differential scanning calorimeter (DSC) and the density of the sintered body.

\section{Results and Discussion}

Figure 1(a) shows the surface morphology of dried alumina nanoparticles used in this study. The size of primary nanoparticles is ranging from 10 to $20 \mathrm{~nm}$ and the primary nanoparticles are agglomerated into a few hundreds $\mathrm{nm}$ in diameters. The shape of the agglomerated nanoparticles is spherical due to reducing the surface energy. Figure 1(b) shows the size distribution of the nanoparticles solved in water solution. When the concentration of $\mathrm{Al}_{2} \mathrm{O}_{3}$ nanoparticles is $50 \mathrm{wt} \%$, the size of nanoparticles exhibits a few micrometers in average size because of the agglomeration among them. As the concentration is reduced into $3 \mathrm{wt} \%$, the size of about $10 \sim 20 \mathrm{~nm}$ 


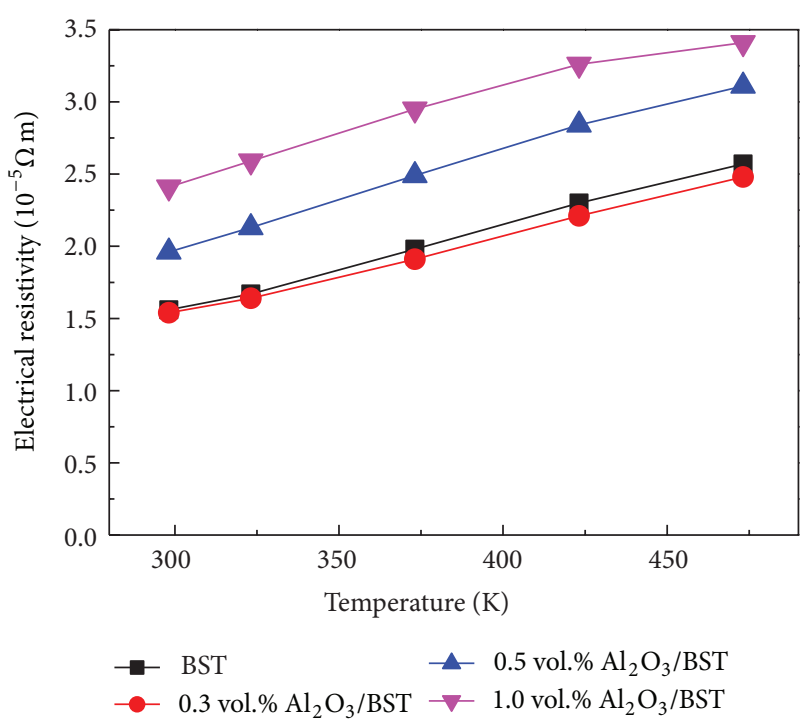

(a)

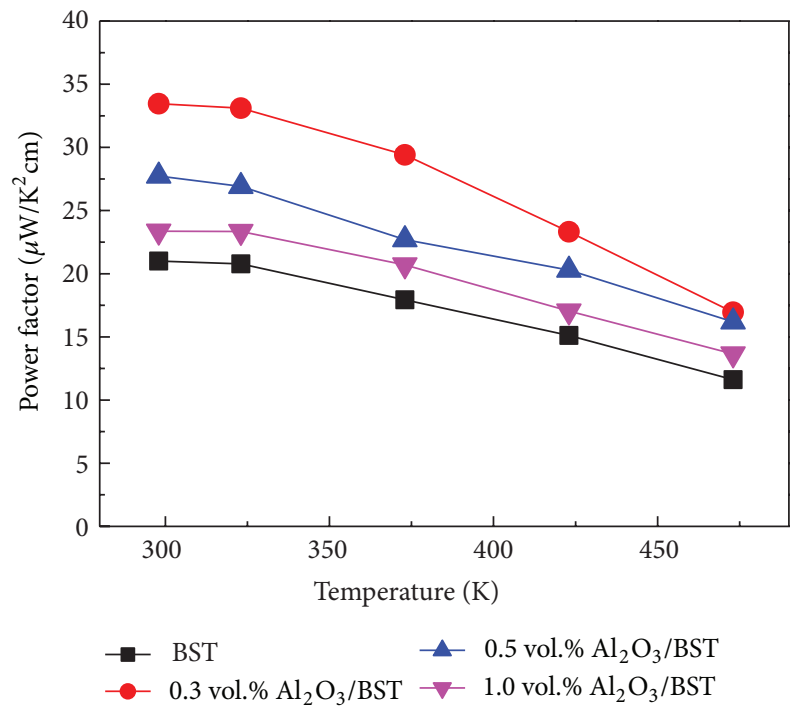

(c)

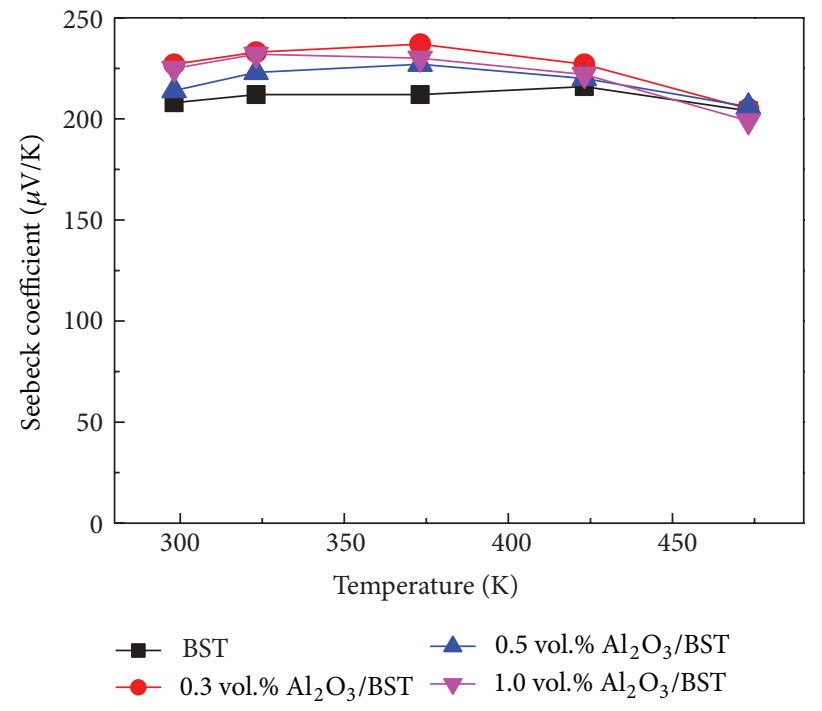

(b)

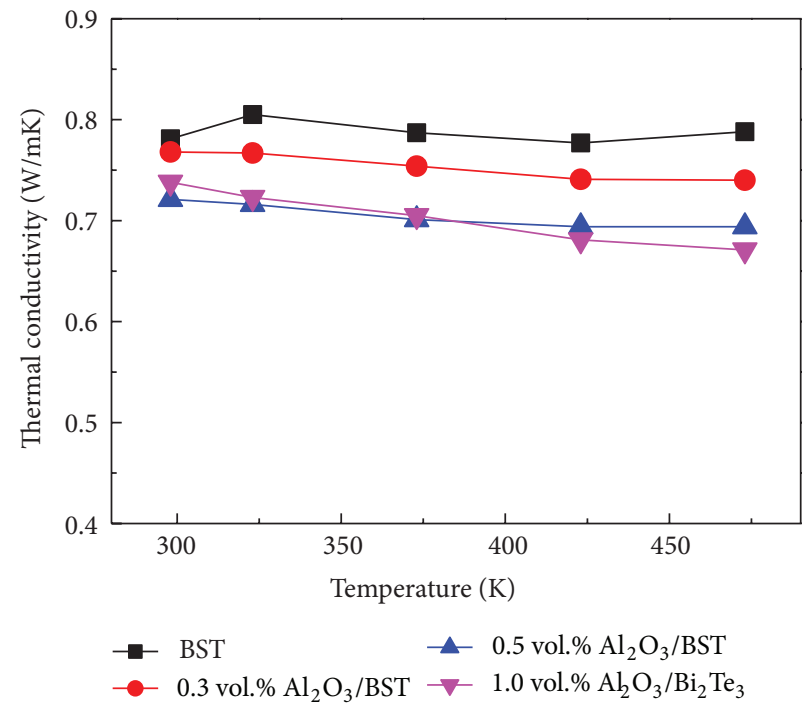

(d)

FIGURE 3: Variation of (a) electrical resistivity, (b) Seebeck coefficient, (c) power factor, and (d) thermal conductivity as a function of temperature ranging from $293 \mathrm{~K}$ to $473 \mathrm{~K}$.

is revealed in the solvent. Thus, the alumina nanoparticles $3 \mathrm{wt} \%$ solution were used for homogeneous mixing with $\mathrm{p}$ type powders. Figure 1(c) shows the morphology of Bi-Sb-Tebased powders prepared from the mechanochemical process (MCP) of the byproducts obtained from the $\mathrm{Cu}$ refining process. The BST powders show $100 \mathrm{~nm}$ of averaged size and it was found that XRD patterns of the fabricated powders are corresponded to $\mathrm{Bi}_{0.5} \mathrm{Sb}_{1.5} \mathrm{Te}_{3}$ phase of JCPDS card no. 491713. The FE-SEM image shown in Figure 1(e) exhibits the morphology of $\mathrm{Al}_{2} \mathrm{O}_{3}$ /BST composite powders prepared after ball milling process. The high-resolution TEM image of the composite powders reveals that alumina nanoparticles are embedded or dispersed in the $\mathrm{Bi}_{0.5} \mathrm{Sb}_{1.5} \mathrm{Te}_{3}$ matrix powders.

Figure 2(a) shows the fracture surface of the $\mathrm{Al}_{2} \mathrm{O}_{3} / \mathrm{BST}$ composite consolidated by SPS process. The SPS provides fast densification time not to agglomerate $\mathrm{Al}_{2} \mathrm{O}_{3} /$ nanoparticles during the consolidation, even though hot pressing method also gives high density of p-type bismuth telluride powders. Typical brittle fracture of bismuth telluride-based materials is observed and some closed pores are partly revealed on the surface. A TEM image of Figure 2(b) exhibits grain boundaries of BST matrix and dispersed $\mathrm{Al}_{2} \mathrm{O}_{3}$ nanoparticles which shows bright region as indicated by the arrows. From the microstructure, it was analyzed that the distribution of $\mathrm{Al}_{2} \mathrm{O}_{3}$ nanoparticles are divided as intragrain type and intergrain type, respectively, as schematically illustrated in Figure 2(c). We expect that this microstructure provides a big benefit reducing total thermal conductivity because of the newly formed extrinsic $\mathrm{Al}_{2} \mathrm{O}_{3}$ / BST interfaces besides the BST grain boundaries. Figure $2(\mathrm{~d})$ shows the variation of XRD patterns of $0.3,0.5$, and 1.0 vol. $\% \mathrm{Al}_{2} \mathrm{O}_{3} / \mathrm{BST}$ composites compared with pure BST materials. All XRD patterns have 
TABLE 1: Comparison of electrical resistivity, carrier density, carrier mobility, and Seebeck coefficient of all samples measured by Hall-effect measurement at room temperature.

\begin{tabular}{lcccc}
\hline Sample & $\begin{array}{c}\text { Electrical resistivity } \\
(\mathrm{m} \Omega \cdot \mathrm{cm})\end{array}$ & $\begin{array}{c}\text { Carrier density } \\
\left(\# / \mathrm{cm}^{3}\right)\end{array}$ & $\begin{array}{c}\text { Carrier mobility } \\
\left(\mathrm{cm}^{2} / \mathrm{Vs}\right)\end{array}$ & $\begin{array}{c}\text { Seebeck coefficient } \\
(\mu \mathrm{V} / \mathrm{K})\end{array}$ \\
\hline BST & 1.52 & $1.81 \times 10^{19}$ & 297 & 205 \\
0.3 vol.\% $\mathrm{Al}_{2} \mathrm{O}_{3} / \mathrm{BST}$ & 1.50 & $1.32 \times 10^{19}$ & 280 & 225 \\
0.5 vol.\% $\mathrm{Al}_{2} \mathrm{O}_{3} / \mathrm{BST}$ & 1.94 & $1.57 \times 10^{19}$ & 226 & 210 \\
1.0 vol.\% $\mathrm{Al}_{2} \mathrm{O}_{3} / \mathrm{BST}$ & 2.46 & $1.45 \times 10^{19}$ & 195 & 225 \\
\hline
\end{tabular}

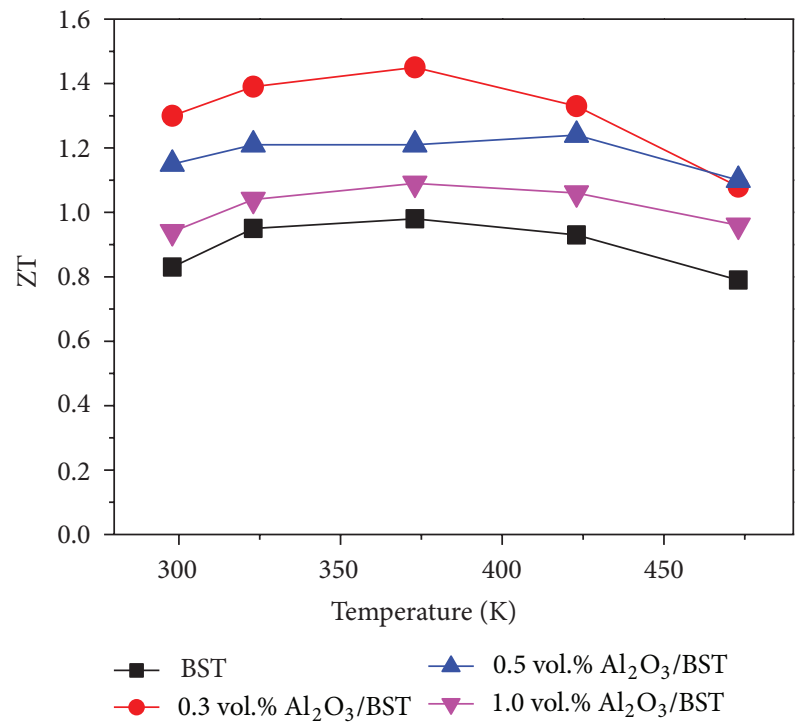

Figure 4: Comparison of dimensionless figures-of-merit (ZT) of pure $\mathrm{BST}$ and $\mathrm{Al}_{2} \mathrm{O}_{3} / \mathrm{BST}$ composites.

no big difference nonetheless contents of $\mathrm{Al}_{2} \mathrm{O}_{3}$ nanoparticles increase. This implies that the addition of alumina nanoparticles do not affect the phase of BST matrix.

Figure 3 shows thermoelectric properties of pure BST and $\mathrm{Al}_{2} \mathrm{O}_{3} / \mathrm{BST}$ composites characterized at the temperature ranging from 293 to $473 \mathrm{~K}$. Figure 3(a) shows the electrical resistivities as a function of temperature. The measured electrical resistivity shows an increasing behavior by increasing temperature. The electrical resistivity of $1.0 \mathrm{vol} . \%$ $\mathrm{Al}_{2} \mathrm{O}_{3} /$ BST composite increases from 1.5 to $2.5 \times 10^{-5} \Omega \mathrm{m}$ when compared at $293 \mathrm{~K}$ and this tendency is still continuously remained by $473 \mathrm{~K}$. Electrical resistivity of $\mathrm{Al}_{2} \mathrm{O}_{3} / \mathrm{BST}$ composite is increased as volume fraction of nonconductive $\mathrm{Al}_{2} \mathrm{O}_{3}$ materials increases. However, 0.3 vol. $\% \mathrm{Al}_{2} \mathrm{O}_{3} / \mathrm{BST}$ composite shows similar electrical resistivity values with pure BST materials. This behavior means that addition of $0.3 \mathrm{vol} . \%$ $\mathrm{Al}_{2} \mathrm{O}_{3}$ nanoparticles does not affect the carrier transporting behaviors of pure BST. As shown in Table 1, carrier mobility of 0.3 vol. $\% \mathrm{Al}_{2} \mathrm{O}_{3} / \mathrm{BST}$ composite does not change compared to pure BST.

The measured Seebeck coefficients of all samples show clearly positive values. These mean that the fabricated samples have p-type semiconducting behaviors. Seebeck coefficients of pure BST vary about $205 \sim 210 \mu \mathrm{V} / \mathrm{K}$ as a function of temperature. The maximum Seebeck coefficient, $235 \mu \mathrm{V} / \mathrm{K}$, is obtained from the $0.3 \mathrm{vol} . \% \mathrm{Al}_{2} \mathrm{O}_{3} / \mathrm{BST}$ composite at $373 \mathrm{~K}$.
As shown in Table 1, carrier density of 0.3 vol. $\% \mathrm{Al}_{2} \mathrm{O}_{3} / \mathrm{BST}$ composite shows the lowest value compared to other samples. It can be considered that the lower Fermi energy level caused by decreasing carrier density results in an increased Seebeck coefficient [13]. Furthermore, the results of Hall effect measurement in Table 1 also show that once $\mathrm{Al}_{2} \mathrm{O}_{3}$ nanoparticles below $10 \mathrm{~nm}$ in diameter are well dispersed under critical volume fraction in the matrix, they affect to carrier mobility and Seebeck coefficient.

Figure 3(c) shows the power factors calculated from the electrical properties. The power factor values of all samples are decreasing with increasing the temperature. However, all power factors of the composites are higher than that of pure BST due to the increased Seebeck coefficients. The peak power factor, $33 \mu \mathrm{W} / \mathrm{K}^{2} \mathrm{~cm}$, was also obtained from the 0.3 vol. $\% \mathrm{Al}_{2} \mathrm{O}_{3} / \mathrm{BST}$ composite at $293 \mathrm{~K}$. This value is 1.7 times higher than $22 \mu \mathrm{W} / \mathrm{K}^{2} \mathrm{~cm}$ of pure BST materials. Although the difference between power factors is reduced as temperature increases, the tendency is continuously remained by $473 \mathrm{~K}$. Figure $3(\mathrm{~d})$ displays variation of thermal conductivity of the composites compared with pure BST materials as a function of temperature. The measured thermal conductivity of BST is about $0.8 \mathrm{~W} / \mathrm{mK}$ and the values are decreased by the addition of alumina nanoparticles. As the volume fraction of alumina nanoparticles increases from 0.3 to 1.0 vol.\%, total thermal conductivity is decreased down to $0.7 \mathrm{~W} / \mathrm{mK}$. It is considered that many interfaces generated from $\mathrm{Al}_{2} \mathrm{O}_{3}$ nanoparticles dispersed in the BST matrix result in the reduction of total thermal conductivity. The result implies that a reduction of the total thermal conductivity in the composites may originate from the newly formed 0.3 vol. $\% \mathrm{Al}_{2} \mathrm{O}_{3} / \mathrm{BST}$ interfaces, which cause carrier and lattice phonon dissipation, as reported previously by the authors in an alumina nanoparticles $/ \mathrm{Bi}_{2} \mathrm{Te}_{3}$ system [14].

Figure 4 shows the dimensionless figures-of-merit (ZT) of pure $\mathrm{BST}$ and the $\mathrm{Al}_{2} \mathrm{O}_{3} / \mathrm{BST}$ composites calculated from the thermoelectric properties displayed in Figure 3. The ZT of the composites shows higher values than those of pure BST as a function of temperature ranging from room temperature to $474 \mathrm{~K}$. Furthermore, the maximum $\mathrm{ZT}$ value, 1.5, has been obtained from the 0.3 vol. $\% \mathrm{Al}_{2} \mathrm{O}_{3} / \mathrm{BST}$ composite at $373 \mathrm{~K}$ due to significantly increased powder factors.

\section{Summary}

In summary, p-type BST nanopowders prepared from MCP were mixed with $0.3,0.5$, and 1.0 vol. $\% \mathrm{Al}_{2} \mathrm{O}_{3}$ nanoparticles by a high-energy ball milling process. The fabricated 
$\mathrm{Al}_{2} \mathrm{O}_{3} / \mathrm{BST}$ composite powders show clear $\mathrm{Bi}_{0.5} \mathrm{Sb}_{1.5} \mathrm{Te}_{3}$ phase as designed. It was found that the thermoelectric properties of the sintered $\mathrm{Al}_{2} \mathrm{O}_{3}$ /BST composite were significantly changed by the contents of alumina nanoparticles. The maximum ZT, 1.5, was obtained from the 0.3 vol.\% $\mathrm{Al}_{2} \mathrm{O}_{3} / \mathrm{BST}$ composite that exhibited high power factor and reduced thermal conductivity. These results clarify that the volume fraction of dispersion agents should be considered for the optimization of electrical and thermal transport behaviors in thermoelectric materials.

\section{Acknowledgments}

This work was supported by the principal R\&D Program of the Korea Institute of Materials Science, Republic of Korea and Kyung Tae Kim appreciates the support by the Basic Science Research Program through the National Research Foundation of Korea (NRF) funded by the Ministry of Education, Science and Technology (Grant no. 2013R1A1A2010377).

\section{References}

[1] R. J. Mehta, Y. Zhang, C. Karthik et al., "A new class of doped nanobulk high-figure-of-merit thermoelectrics by scalable bottom-up assembly," Nature Materials, vol. 11, no. 3, pp. 233-240, 2012.

[2] X. B. Zhao, X. H. Ji, Y. H. Zhang, T. J. Zhu, J. P. Tu, and X. B. Zhang, "Bismuth telluride nanotubes and the effects on the thermoelectric properties of nanotube-containing nanocomposites," Applied Physics Letters, vol. 86, Article ID 062111, 2005.

[3] Y. Q. Cao, X. B. Zhao, T. J. Zhu, X. B. Zhang, and J. P. Tu, "Syntheses and thermoelectric properties of $\mathrm{Bi}_{2} \mathrm{Te}_{3} \mathrm{Sb}_{2} \mathrm{Te}_{3}$ bulk nanocomposites with laminated nanostructure," Applied Physics Letters, vol. 92, Article ID 143106, 2008.

[4] W. Xie, X. Tang, Y. Yan, Q. Zhang, and T. M. Tritt, "Unique nanostructures and enhanced thermoelectric performance of melt-spun BiSbTe alloys," Applied Physics Letters, vol. 94, Article ID 102111, 2009.

[5] B. Poudel, Q. Hao, Y. Ma et al., "High-thermoelectric performance of nanostructured bismuth antimony telluride bulk alloys," Science, vol. 320, no. 5876, pp. 634-638, 2008.

[6] L.-D. Zhao, B.-P. Zhang, J.-F. Li, M. Zhou, W.-S. Liu, and J. Liu, "Thermoelectric and mechanical properties of nano-SiCdispersed $\mathrm{Bi}_{2} \mathrm{Te}_{3}$ fabricated by mechanical alloying and spark plasma sintering," Journal of Alloys and Compounds, vol. 455, no. 1-2, pp. 259-264, 2008.

[7] S. Fan, J. Zhao, Q. Yan, J. Ma, and H. H. Hng, "Influence of nanoinclusions on thermoelectric properties of n-type $\mathrm{Bi}_{2} \mathrm{Te}_{3}$ nanocomposites," Journal of Electronic Materials, vol. 40, no. 5, pp. 1018-1023, 2011.

[8] G.-D. Zhan, J. D. Kuntz, A. K. Mukherjee, P. Zhu, and K. Koumoto, "Thermoelectric properties of carbon nanotube/ceramic nanocomposites," Scripta Materialia, vol. 54, no. 1, pp. 77-82, 2006.

[9] K. T. Kim, S. Y. Choi, E. H. Shin et al., "The influence of CNTs on the thermoelectric properties of a CNT/ $\mathrm{Bi}_{2} \mathrm{Te}_{3}$ composite," Carbon, vol. 52, pp. 541-549, 2013.

[10] Y. Zhang, X. L. Wang, W. K. Yeoh, R. K. Zeng, and C. Zhang, "Electrical and thermoelectric properties of single-wall carbon nanotube doped $\mathrm{Bi}_{2} \mathrm{Te}_{3}$," Applied Physics Letters, vol. 101, Article ID 031909, 2012.
[11] K. T. Kim, K. J. Kim, and G. H. Ha, “Thermoelectric properties of P-type bismuth telluride powders synthesized by a mechanochemical process," Electronic Materials Letters, vol. 6, no. 4, pp. 177-180, 2010.

[12] X. A. Fan, J. Y. Yang, R. G. Chen, W. Zhu, and S. Q. Bao, "Phase transformation and thermoelectric properties of p-type $\left(\mathrm{Bi}_{2} \mathrm{Te}_{3}\right)_{0.25}\left(\mathrm{Sb}_{2} \mathrm{Te}_{3}\right)_{0.75}$ prepared by mechanical alloying and hot pressing," Materials Science and Engineering A, vol. 438440, pp. 190-193, 2006.

[13] K. T. Kim, T. S. Lim, and G. H. Ha, "Improvement in thermoelectric properties of $\mathrm{N}$-type bismuth telluride nanopowders by hydrogen reduction treatment," Reviews on Advanced Materials Science, vol. 28, no. 2, pp. 196-199, 2011.

[14] K. T. Kim, H. Y. Koo, G. G. Lee, and G. H. Ha, "Synthesis of alumina nanoparticle-embedded-bismuth telluride matrix thermoelectric composite powders," Materials Letters, vol. 82, pp. 141-144, 2012. 

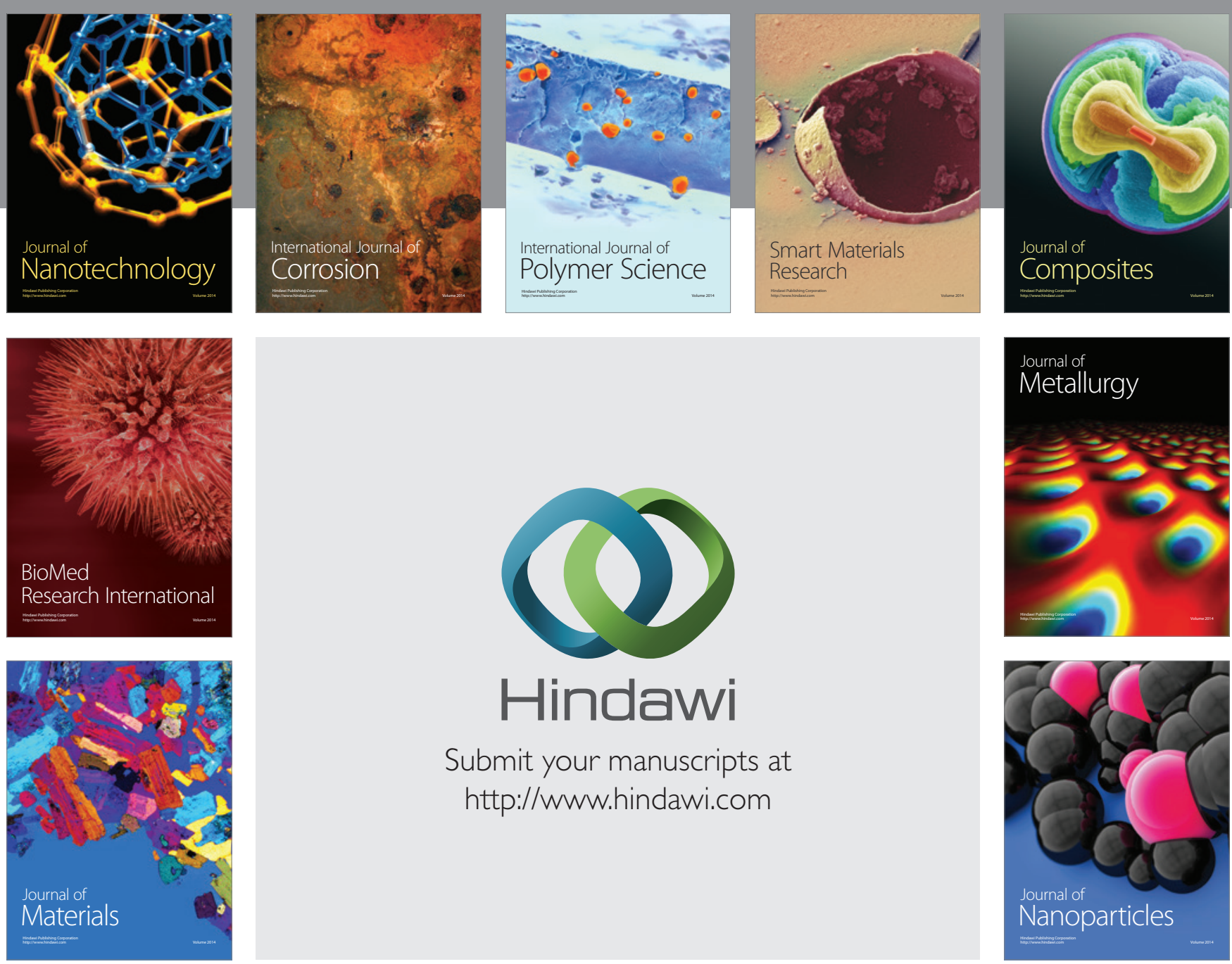

Submit your manuscripts at http://www.hindawi.com
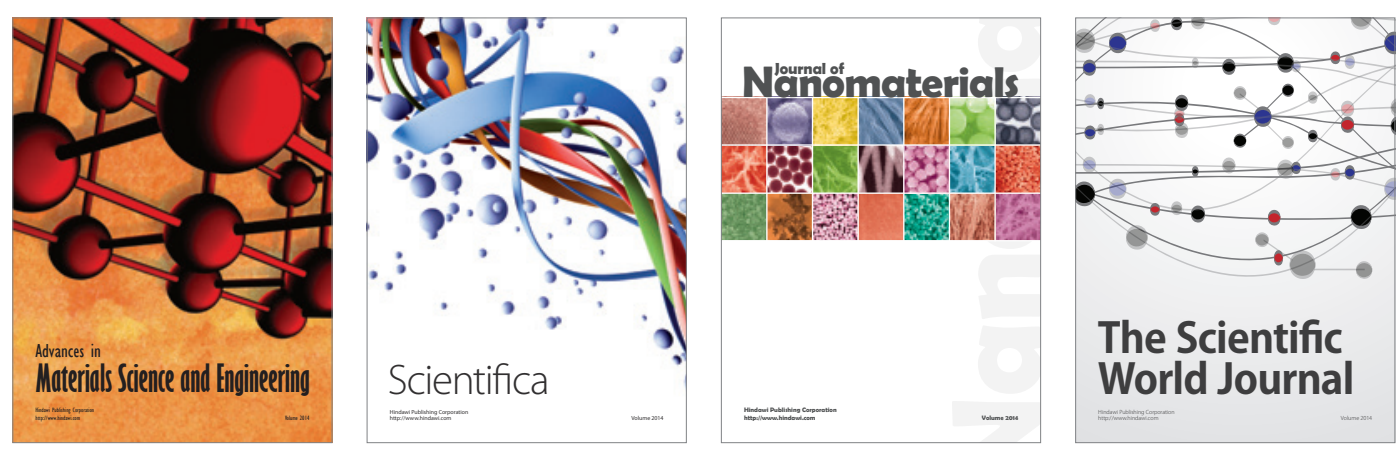

\section{The Scientific World Journal}
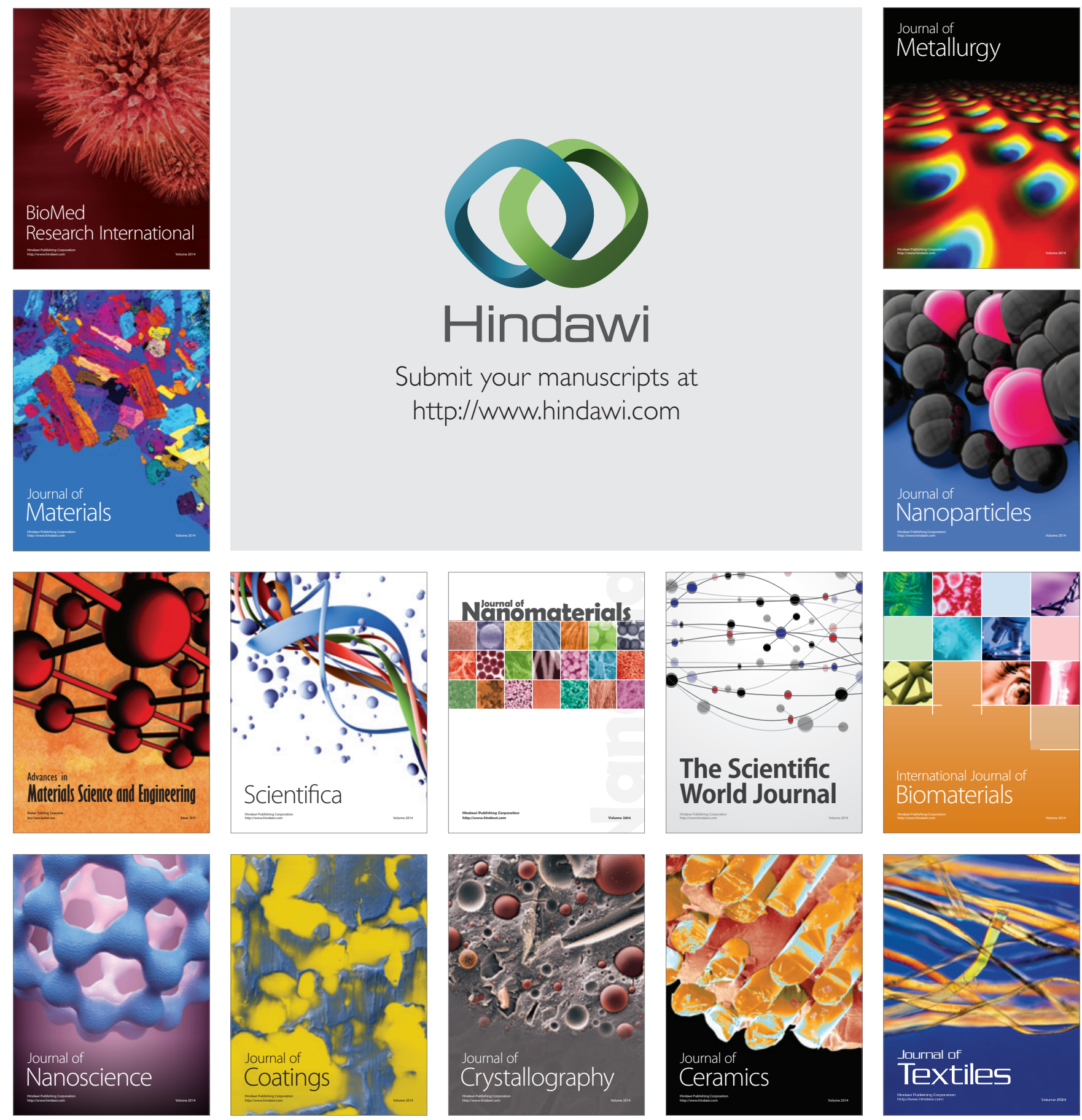